\title{
Diretrizes para a elaboração do PEl como instrumento de avaliação para educando com autismo: um estudo interventivo
}

\author{
Debora Mara Pereira* \\ Débora Regina de Paula Nunes**
}

\section{Resumo}

Resultados de pesquisas recentes revelam as dificuldades dos sistemas regulares de ensino em oferecer um currículo escolar que atenda as demandas acadêmicas de educandos com Transtorno do Espectro Autista (TEA). Dentre os fatores que contribuem para esse fenômeno, evidencia-se a precária formação docente e a escassez de estratégias que promovam a acessibilidade. Como consequência, é registrada a deficitária participação acadêmica desse alunado na sala de aula comum. O objetivo desse trabalho foi propor diretrizes para elaboração de um Plano Educacional Individualizado (PEI). Trata-se de instrumento de organização curricular e de avaliaçáo acadêmica direcionado para um estudante com TEA, inserido em contexto pré-escolar. Os resultados, produzidos por meio de um delineamento quase-experimental intrassujeito, indicaram mudanças qualitativas e quantitativas na participação do aluno nas tarefas acadêmicas após o programa de intervenção.

Palavras-chave: Autismo; Plano educacional individualizado; Educação inclusiva.

\footnotetext{
* Professora da rede pública, Panamirim, Rio Grande do Norte, Brasil.

** Professora doutora da Universidade Federal do Rio Grande do Norte (UFRN), Natal, Rio Grande do Norte, Brasil.
} 


\section{Guidelines for the development of the IEP as an evaluation tool for students with autism: an interventional study}

\section{Abstract}

Recent research results reveal the difficulties of regular education systems in providing a school curriculum that meets the academic demands of learners with Autism Spectrum Disorder (ASD). Among the factors that contribute to this phenomenon are the precarious teacher training and the lack of strategies that promote accessibility. As a consequence, the student's lack of academic participation is registered in the common classroom. The purpose of this work was to propose guidelines for the elaboration of an Individualized Educational Plan (IEP), an instrument of curricular organization and evaluation for a student with ASD, enrolled in a pre-school context. The results, produced through an intrasubject quasi-experimental design, indicated qualitative and quantitative changes in student participation in academic tasks after the intervention program.

Keywords: Autism; Individualized educational plan; Inclusive education.

\section{Directrices para la elaboración del IEP como una herramienta de evaluación para educar con autismo: un estudio de intervención}

\section{Resumen}

Los resultados de investigaciones recientes revelan las dificultades de los sistemas regulares de enseńanza en ofrecer un currículo escolar que atienda las demandas académicas de educandos con Trastorno del Espectro Autista (TEA). Entre los factores que contribuyen a este fenómeno se evidencia la precaria formación docente y la escasez de estrategias que promuevan la accesibilidad. Como consecuencia, se registra la deficiente participación académica de ese alumnado en el aula común. El objetivo de este trabajo fue proponer directrices para la elaboración de un Plan Educativo Individualizado (PEI). Se trata de un instrumento de organización curricular y de evaluación académica dirigido a un estudiante con TEA, inserto en contexto preescolar. Los resultados, producidos a través de un delineamiento cuasi experimental intra-sujeto, indicaron cambios cualitativos y cuantitativos en la participación del alumno en las tareas académicas después del programa de intervención.

Palabras-clave: Autismo; Plan educativo individualizado; Educación inclusiva. 


\section{Introdução}

Dados do Censo Escolar 2017 revelam expressivo aumento nas últimas décadas, no número de matrículas, na escola comum, de alunos diagnosticados com Transtorno do Espectro do Autismo (TEA; BRASIL, 2018). A despeito desses registros, estudos apontam prejuízos na qualidade do ensino ofertado e, particularmente, no progresso acadêmico desse alunado (NEVES; ANTONELLI; SILVA; CAPELLINI, 2014; NUNES; SCHMIDT; AZEVEDO 2013; OLIVIERA; PAULA, 2012). Dentre os fatores contribuintes para a ocorrência de fenômenos dessa natureza destacam-se a deficitária formação docente e a escassez de adaptaçóes curriculares promovidas pelas escolas. Esses mesmos fatores prejudicam, sobremaneira, o acesso dessa população aos conhecimentos acadêmicos e ao repertório de competências e de habilidades funcionais a serem desenvolvidas no contexto escolar (NUNES et al., 2013; NOZI E VITALIANO, 2012; OLIVIERA; PAULA, 2012; SCHMIDT et al., 2016).

Deflagra-se, neste cenário, a relevância do uso do Plano Educacional Individualizado (PEI), como instrumento que promove a acessibilidade curricular. Trata-se de recurso pedagógico, centrado no aluno, que estabelece metas acadêmicas e funcionais para os educandos com deficiência (SMITH, 2008). Concebido como um mapa educacional, o PEI descreve, essencialmente, o nível atual de desempenho do aluno e os objetivos educacionais de curto e de longo prazo, pareados com o currículo destinado ao ensino regular. $\mathrm{O}$ alcance dos objetivos escolares é favorecido pelo uso de formas alternativas e individualizadas de ensino e avaliação, que se adéquam às especificidades cognitivas, sensoriais, sociocomunicativas e comportamentais do educando. Vale destacar que o referido instrumento trata da oferta de serviços educacionais específicos, além da maneira com que o desempenho do aluno será mensurado.

O objetivo deste artigo é relatar os resultados da análise dos efeitos da implementação do PEI, no processo de escolarização de um aluno diagnosticado com TEA, inserido em uma escola regular. Trata-se de pesquisa colaborativa de natureza quase-experimental, na modalidade intrasujeito.

\section{Método}

\section{Participantes}

Os sujeitos participantes foram João, os seus pais e três professoras, sendo uma titular, uma auxiliar e uma de apoio pedagógico. João era filho único, tinha 5 anos de idade e estava regularmente matriculado no nível IV da educação infantil, em uma escola regular. O diagnóstico apontava autismo moderado, de acordo com resultado de avaliação baseado no Childhood Autism Rating Scale - CARS (PEREIRA et. al., 2008), escala administrada no início da pesquisa. O menino não se comunicava verbalmente e utilizava limitado número de gestos não convencionais como forma de expressão. Evidenciava dificuldade em interagir com seus pares, estereotipias motoras e inflexibilidade comportamental. Joáo era atendido semanalmente por uma terapeuta ocupacional e pela professora de apoio pedagógico, em contexto não escolar. 
Ambas as professoras, a titular e a de apoio pedagógico eram licenciadas em Pedagogia, enquanto a auxiliar, na época, frequentava o $4^{\circ}$ período do curso. Das três professoras, apenas a auxiliar não tivera contato com educandos com TEA. O pai de João (40 anos), engenheiro civil e a mãe ( 44 anos) dona de casa, residiam em um bairro de classe-média alta.

\section{Agente de intervenção}

A primeira autora, denominada de pesquisadora, atuou como agente de intervenção. Ela era pedagoga com experiência na educação de alunos com TEA e, na época, era aluna do $2^{\circ}$ ano do curso de Mestrado em Educaçáo.

Local

Os dados foram coletados em uma escola particular, localizada na cidade de Natal (RN). O contexto de intervenção selecionado foi a sala de aula, durante a realização de duas rotinas, a de escrita e de lanche.

\section{Delineamento de pesquisa}

Um delineamento de pesquisa quase experimental intrassujeito (A-B) foi adotado. O PEI, compreendido como instrumento de avaliação do desenvolvimento educacional de estudantes com deficiência, elaborado por equipe multiprofissional foi configurado como variável independente do estudo.

Dois conjuntos de variáveis dependentes foram analisados, sendo um de natureza qualitativa e o outro, quantitativa. O primeiro conjunto contemplou duas variáveis: (a) o desenvolvimento das produçóes escritas e (b) a qualidade da participação do aluno na rotina de lanche. Na primeira, as tarefas escritas produzidas durante a fase de linha de base foram comparadas com as tarefas executadas durante a fase de intervenção. A teoria da Psicogênese da Língua Escrita, elaborada por Emília Ferreiro e Ana Teberosky (FERREIRO E TEBEROSKY, 1999), foi empregada para a apreciação do material.

A variável qualidade da participação na rotina de lanche foi avaliada considerando-se os comportamentos apropriados, emitidos pelo aluno no cumprimento da rotina de alimentaçáo, como sentar-se no local adequado, utilizar um copo, esperar a vez, solicitar o lanche aos professores, etc.

As variáveis dependentes, de natureza quantitativa, diziam respeito ao tempo de permanência do aluno nas rotinas de escrita e lanche. Essas variáveis foram mensuradas por meio de registro de frequência de evento (FAGUNDES, 2006).

Uma assistente de pesquisa, previamente treinada, e a pesquisadora atuaram, respectivamente, como primeira e segunda juízas das sessóes experimentais que avaliaram a permanência de João nas tarefas. $\mathrm{O}$ índice médio de concordância, calculado por meio do modelo de Fagundes (2006), para a atividade de escrita foi de $76 \%$ e do lanche, de 94\%. 


\section{Instrumentos}

Diários de campo, roteiros de entrevista e o instrumento CARS (PEREIRA, et al. 2008) foram os instrumentos utilizados.

\section{Equipamentos}

Os equipamentos incluíram uma câmera videofotográfica e um notebook.

\section{Procedimentos}

Depois de submetido e aprovado, o projeto de pesquisa (Parecer no 63139) foi operacionalizado em quatro etapas distintas: caracterização, linha de base, intervenção e validação social. A fase de caracterização contemplou entrevistas com os pais e com as professoras de Joáo, bem como a identificação das rotinas escolares que seriam foco da intervenção.

$\mathrm{Na}$ linha de base, as professoras (titular e auxiliar) foram instruídas a interagir livremente com o aluno nas duas rotinas selecionadas (lanche e escrita). As sessôes foram videografadas e as variáveis dependentes, analisadas. O critério para o término dessa fase foi a estabilidade ou tendência descendente no tempo de permanência de João na tarefa em uma das duas rotinas analisadas.

A intervenção foi realizada em três fases, compreendendo 30 sessóes experimentais. A primeira, denominada fase de reflexão, teve como objetivo auxiliar a professora titular a analisar os conteúdos e objetivos do projeto curricular da turma, considerando as demandas do educando com autismo. Nessa etapa, por meio da prática de autoscopia ${ }^{1}$, as professoras analisaram as sessóes videografadas das rotinas e, com o auxílio da pesquisadora, ponderaram sobre possibilidades de participação do aluno nas atividades.

$\mathrm{Na}$ segunda fase da intervenção foi prevista uma reuniáo multiprofissional, incluindo os pais de João, as professoras, a coordenadora pedagógica, a psicóloga escolar a orientadora pedagógica e a terapeuta ocupacional. O objetivo desse encontro foi apresentar um modelo de PEI à equipe e identificar as contribuiçóes de cada um dos membros.

Por fim, na terceira fase interventiva, o PEI foi estruturado e operacionalizado pelas duas professoras da escola. Configurou-se, nesse processo, um movimento dialógico que envolvia planejamentos, aplicação das açóes planejadas e reflexão sobre a prática docente, por meio da apreciação do material videografado. Na última etapa da pesquisa, uma entrevista semiestruturada com a professora titular foi realizada com o intuito de avaliar a validade social do estudo.

\section{Resultados e discussão}

Os dados para a produção dos resultados foram extraídos dos diários de campo, dos relatórios de planejamento, da análise das sessóes videografadas, de registros fotográficos e das entrevistas. No total, foram realizadas 36 sessões ( 6 de linha de base e 30 de intervenção), conduzidas durante 8 meses. 
A elaboração do PEI é um processo coletivo, envolvendo as expectativas dos pais, professores e demais profissionais que trabalham com o aluno (SMITH, 2008). Nesse estudo, cada grupo foi, em um primeiro momento, ouvido individualmente.

A família foi a primeira a ser consultada. Durante a entrevista individual realizada, a mãe revelou que suas expectativas educacionais para seu filho eram que:

[...] ele conseguisse identificar o nomezinho dele, que ele tá quase conseguindo, eu acho, se socializar mais com as crianças... de aprender as letrinhas, o a, e, i, o, u, identificar cores, os numerozinhos, até o $10[\ldots]$ tentar ter algum aprendizado no sentido educacional. (Mãe, 2012).

Em outras palavras, a família evidenciava o desejo de que João desenvolvesse habilidades acadêmicas básicas, que ainda não possuía. Em termos de expectativas para o futuro, a mãe declarou: "[...] meu sonho é que João fosse um Henry... já formado, falando, eu espero que ele fale” (Mãe, 2012).

Nesse segmento, a mãe compara João a Henry, um jovem conhecido, com autismo, que concluíra o curso superior. Além da expectativa de que João ingressasse na universidade, a resposta da mãe revela a esperança de que o filho falasse em alguma fase da vida. Vale ressaltar que tais expectaçóes, por fatores intrínsecos ao autismo, nem sempre podem ser atendidas. A literatura registra que mais da metade das pessoas com TEA não desenvolve, para fins comunicativos, a fala funcional (GANZ, 2015). Esse poderia ser o caso do aluno. Embora os esforços para que João se comunicasse verbalmente não devessem cessar, era preciso considerar outras possibilidades, como o uso da Comunicação Alternativa e Ampliada (CAA). Essa prática interventiva tem como objetivo minimizar, de forma temporária ou permanente, os prejuízos na comunicaçáo expressiva e receptiva, por meio do uso de gestos, sinais manuais, pranchas de comunicação, sintetizadores de voz, dentre outros recursos (GANZ, 2015).

Com base em material videografado e registros de diário de campo, a pesquisadora selecionou as atividades de escrita e lanche como foco das açóes interventivas. No primeiro caso, os resultados revelaram que João era tipicamente instruído a realizar atividades paralelas, não relacionadas ao desenvolvimento da escrita. Sua participação era restrita a desenhar espontaneamente. Nessas ocasióes era observado que, enquanto a turma realizava atividades variadas de escrita, a ele eram propostas tarefas de desenho livre, sem orientaçôes ou objetivos definidos. Assim, permanecia em sua carteira realizando movimentos circulares na folha de papel, conforme observado na figura 1 a seguir. 
Figura 1 - Desenho livre

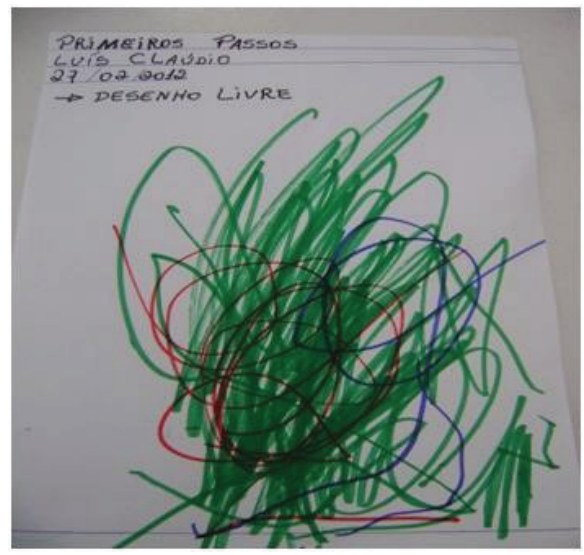

Fonte própria.

De acordo com Ferreiro e Teberosky (1999) os rabiscos representam as primeiras expressôes de escrita da criança. Nessa primeira fase, não há diferenciação entre o desenho e a escrita. Linhas e traços são projetados espontaneamente, sem a intenção de representar a imagem de um objeto. Esses rabiscos vão, gradativamente, evoluindo de acordo com a influência biológica, social e cultural da criança, além de suas características individuais (MOREIRA, 1984).

A importância do exercício da escrita é salientada nos Referenciais Curriculares Nacionais de Educação Infantil (RCNEI; BRASIL, 1998). De acordo com o referido documento, as atividades de escrita para alunos de quatro a seis anos devem contemplar:

[...] situaçôes cotidianas nas quais se faz necessário uso da escrita; escrita do próprio nome em situações em que isso é necessário; produçáo de textos individuais e/ou coletivos ditados oralmente ao professor para diversos fins; prática de escrita de próprio punho, utilizando o conhecimento de que dispóe, no momento, sobre o sistema de escrita em língua materna. (BRASIL, 1998, p. 145)

$\mathrm{Na}$ situação de lanche, era observado que João não se comunicava para solicitar seus alimentos. Em geral, eles eram prontamente entregues ou dados pelas professoras. Vale, ainda, ressaltar que o aluno utilizava uma mamadeira e, diferente dos colegas, não consumia os alimentos da escola, conforme observado na figura 2 . 
Figura 2 - João tomando suco na mamadeira

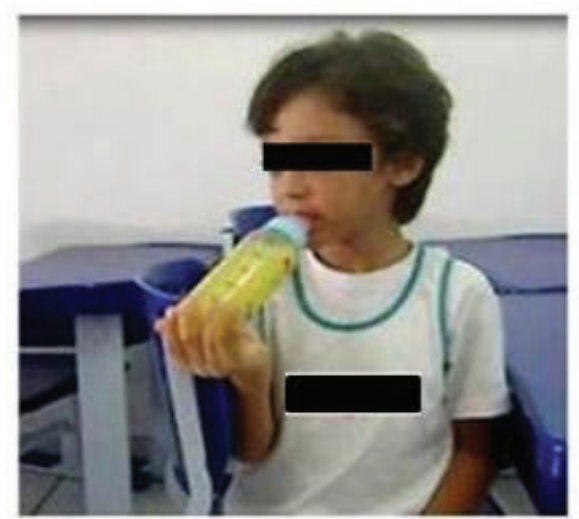

Fonte própria.

Em relação ao consumo de alimentos, o RCNEI aponta que o professor deve:

[...] possibilitar às crianças oportunidades que propiciem o acesso e conhecimento sobre os diversos alimentos, o desenvolvimento de habilidades para escolher sua alimentação, servir-se e alimentar-se com segurança, prazer e independência (BRASIL, 1998, p. 56).

Dessa forma, o RCNEI considera a alimentação como componente curricular, que proporciona oportunidades de comunicação e desenvolvimento de autonomia.

Por fim, foi observada pouca colaboração entre as docentes durante essas atividades. Enquanto a professora titular se responsabilizava pelos alunos com desenvolvimento típico, a professora auxiliar tinha a função de orientar e "cuidar" de João. Em muitas situaçốes demonstrava não saber como proceder para atender às necessidades desse aluno.

O emprego da autoscopia durante a primeira etapa da intervenção possibilitou que as docentes ponderassem sobre a participação do aluno nas rotinas alvo, assim como das práticas pedagógicas implementadas. Ao assistir aos vídeos de linha de base, as professoras reconheceram a limitada participação do aluno, assim como a carência de estratégias efetivas de ensino utilizadas. Isso é ilustrado no seguinte comentário da professora titular:

Aqui ele não fez nada e é isso que eu não quero... nem ninguém chegou até ele... a turma é bem agitada... tenho que preparar as atividades, dar atenção a todos, mas nem sempre é possível. (Professora titular, 2012) 
Nesse segmento, a falta de engajamento de João em atividade curricular é atribuída à carência de apoio e à sobrecarga de tarefas. Vale destacar que esses fatores, assim como as turmas numerosas, a falta de capacitaçáo e o pouco tempo do professor regente de realizar trabalhos individualizados interferem no processo de ensino -aprendizagem do educando com deficiência (GLAT; PLETSCH, 2011).

O desconforto em atuar com o aluno é evidenciado na fala da professora auxiliar que, ao assistir ao vídeo, declara:

Eu me senti péssima... a sensação de não conseguir, sabe? de fraquejar. Pensei em fugir... mudei de lugar pra ver se ele se concentrava, fui pra frente dele, mas preferi ficar ao lado dele, acho que foi melhor. (Professora auxiliar, 2012)

A sensação de impotência sugerida pela professora é retratada por docentes que atuam com educandos com autismo investigados em outros estudos (NUNES et al., 2013; SCHMIDT et al., 2016).

A reunião multiprofissional agendada na segunda etapa da intervençáo sofreu intercorrências. A terapeuta ocupacional não pôde comparecer e a coordenadora da escola vetou a participação dos pais, alegando que poderiam náo compreender a proposta. Esse empecilho sugere que, no Brasil, a participação da família é pouco valorizada na escola (BENTES, COLARES E SOARES, 2012). Polonia e Dessen (2005) salientam que as limitaçóes nessa participação podem advir, dentre outros fatores, do receio dos docentes de serem monitorados e fiscalizados pelos pais dos alunos ou da percepção de que os responsáveis não têm capacidade ou condiçóes de auxiliar os filhos.

A despeito da ausência da terapeuta e da família, a reunião foi realizada, tendo como participantes a equipe escolar e a professora de apoio pedagógico. Durante 90 minutos o grupo discutiu as especificidades do PEI e os procedimentos de ensino que poderiam ser usados com Joáo, no contexto da sala de aula.

$\mathrm{Na}$ terceira fase da intervenção, 12 reunióes de planejamento foram conduzidas com a professora titular e com a auxiliar. A terapeuta ocupacional e a professora de apoio pedagógico, impossibilitadas de participar dos encontros na escola, reuniram-se individualmente com a pesquisadora, que atuou como mediadora da equipe. A terapeuta elucidou as demandas sensoriais e motoras do aluno, sugerindo a eliminação de estímulos e uso de materiais com distintas texturas. A professora de apoio teve a função de dar continuidade ao plano traçado durante as sessôes de apoio pedagógico.

Com base nas metas acadêmicas da turma, nas expectativas dos pais de João e dos demais profissionais envolvidos, os seguintes objetivos, metodologias e recursos didáticos foram incluídos no PEI do aluno (Quadro 1). 
Quadro 1 - Objetivos, Metodologias e Recursos didáticos no ensino de Joẫo

\begin{tabular}{|c|c|c|c|}
\hline HABILIDADES & $\begin{array}{l}\text { OBJETIVOS TURMA } \\
\text { GERAIS PARA A }\end{array}$ & $\begin{array}{l}\text { OBJETIVOS PARA } \\
\text { JOÂO }\end{array}$ & $\begin{array}{l}\text { METODOLOGIA E RECURSOS } \\
\text { DIDÁTICOS PARA JOÁO }\end{array}$ \\
\hline Escrita & $\begin{array}{l}\text { 1. Identificar letras e pa- } \\
\text { lavras impressas; } \\
\text { 2. Escrever o nome; } \\
\text { 3. Comparar o próprio } \\
\text { nome com os nomes dos } \\
\text { colegas; } \\
\text { 4. Copiar o nome da es- } \\
\text { cola e a data; } \\
\text { 5. Relatar experiências } \\
\text { vividas; } \\
\text { 6. Narrar fatos; } \\
\text { 7. Produzir textos cole- } \\
\text { tivos; } \\
\text { 8. Utilizar a escrita (es- } \\
\text { pontânea) em situaçôes } \\
\text { cotidianas; } \\
\text { 9. Expor e defender } \\
\text { ideias (pontos de vista) }\end{array}$ & $\begin{array}{l}\text { 1. Identificar as letras } \\
\text { do nome; } \\
\text { 2. Escrever o nome; } \\
\text { 3. Identificar as } \\
\text { letras do nome da } \\
\text { escola; } \\
\text { 4. Copiar o nome da } \\
\text { escola; } \\
\text { 5. Registrar as ativi- } \\
\text { dades desenvolvidas } \\
\text { no final de semana; } \\
\text { 6. Parear letras e pa- } \\
\text { lavras; } \\
\text { 7. Ampliar o vocabu- } \\
\text { lário sobre os proje- } \\
\text { tos trabalhados; } \\
\text { 8. Estruturar esque- } \\
\text { ma corporal no de- } \\
\text { senho; } \\
\text { 9. Construir novas } \\
\text { formas/ esquemas } \\
\text { representativos no } \\
\text { desenho. }\end{array}$ & $\begin{array}{l}\text { 1. Utilizar atividades de pareamen- } \\
\text { to; } \\
\text { 2. Usar desenhos, figuras e imagens } \\
\text { nas atividades; } \\
\text { 3. Fazer uso de modelos de desenho } \\
\text { e escrita; } \\
\text { 4. Utilizar atividades de cobrir letras } \\
\text { com diversos materiais, utilizando } \\
\text { letras vazadas e pontilhadas, com } \\
\text { vários níveis de dificuldade. } \\
\text { 5. Utilizar formas năo verbais de co- } \\
\text { municaçáo (expressóes faciais engra- } \\
\text { çadas, prosódias divertidas, contato } \\
\text { físico). } \\
\text { 6. Realizar atividades corporais e } \\
\text { sensoriais } \\
\text { 7. Disponibilizar um sistema de } \\
\text { CAA em forma de cartōes avulsos, } \\
\text { utilizando sistema de troca de figu- } \\
\text { ras; } \\
\text { 8. Inserir João em trabalhos de gru- } \\
\text { po. }\end{array}$ \\
\hline Lanche & $\begin{array}{l}\text { 1. Fazer uso adequado } \\
\text { dos materiais escolares; } \\
\text { 2. Consumir alimentos } \\
\text { saudáveis; } \\
\text { 3. Solicitar o lanche ao } \\
\text { professor; } \\
\text { 4. Compartilhar o lan- } \\
\text { che com os colegas; }\end{array}$ & $\begin{array}{l}\text { 1. Consumir suco no } \\
\text { copo da escola; } \\
\text { 2. Consumir alimen- } \\
\text { tos saudáveis (lanche } \\
\text { da escola); } \\
\text { 3. Solicitar o lanche } \\
\text { ao professor; }\end{array}$ & $\begin{array}{l}\text { 1. Disponibilizar cartóes com ima- } \\
\text { gens sobre objetos e rotinas da es- } \\
\text { cola; } \\
\text { 2. Disponibilizar um copo com } \\
\text { bico e um copo descartável; } \\
\text { Organizar o ambiente de forma a } \\
\text { instigar que o aluno solicite os ali- } \\
\text { mentos espontaneamente }\end{array}$ \\
\hline
\end{tabular}

Fonte própria.

Conforme observado no quadro, os objetivos de João eram equivalentes aos traçados para o grupo e as metodologias incluíam o uso de práticas comuns utilizadas em atividades de escrita na Educação Infantil, mas pouco exploradas pelas professoras. Dentre elas destacam-se o uso da letra vazada, atividades de pareamento e exercícios de cobrir. Por fim, foi solicitado que as docentes utilizassem formas não verbais de comunicação, como expressốes faciais e contato físico. Açôes propositivas dessa natureza favorecem, na perspectiva sociointeracionista de Feurnstein e colaboradores $(1987)^{2}$, o engajamento e a aprendizagem. 
Em termos de recursos, merece relevo a inclusão de um sistema de CAA, configurado como cartôes avulsos, que deveriam ser utilizados como sistema de troca de figuras. Para ter acesso a um objeto, João deveria entregar o pictograma a um interlocutor que, em troca, lhe entregaria o objeto desejado. O uso da CAA foi favorecido pela forma como a rotina do lanche foi reestruturada. Ou seja, as professoras foram instruídas a esperar que João solicitasse os alimentos ao invés de entrega-los prontamente ao aluno. Por fim, foi sugerida a substituição da mamadeira pelo copo e o consumo de alimentos da escola.

Depois de estruturado, as docentes iniciaram a implementação do PEI. A avaliação do desempenho do aluno, tendo como base os objetivos traçados (quadro 1), foi feita durante as reunióes com a pesquisadora, quando o material videografado das sessóes era apreciado pelas professoras. Ademais, foram consideradas as produçóes escritas do aluno.

As falas das docentes durantes as sessões de autoscopia, após a implementação do PEI, pareceram mais animadoras. Quando solicitada a falar do que observara de positivo na sessão interventiva, a professora titular relatou:

\begin{abstract}
As estratégias de ensinos como, o uso dos cartóes da figura para ele se comunicar, trabalhar com as coisas da realidade de Joáo, o uso de imagens, os cartóes do lanche, as fotos dele sobre o final de semana, a construção do corpo com bonecos, o modelo para ele perceber o movimento, atividade com os outros colegas também, o lúdico, a afetividade foram essenciais para o desenvolvimento dele. (Professora titular, 2012).
\end{abstract}

Nessa fala, a professora salienta a efetividade de utilizar a CAA durante o lanche, assim como a importância de inserir artefatos do cotidiano da criança, atividades lúdicas e a afetividade na realização das tarefas. De fato, dados de pesquisa têm sugerido que o uso de recursos visuais, associado a outras formas não verbais de comunicação, incluindo expressôes de afeto favorecem o engajamento e a aprendizagem do aluno com TEA (FARIAS; MARANHÃO; CUNHA, 2008; MACÊDO; NUNES, 2016).

A "aprendizagem com outros colegas" citada pela professora titular diz respeito à aprendizagem cooperativa (LOPES; SILVA, 2009), mediada pela professora, que passou a incluir João nas atividades. Como resultado, os registros revelaram melhorias no nível de interação com a turma, conforme evidenciado nas figuras 3 e 4 . 
Figura 3 - Atividade coletiva com massa de modelar

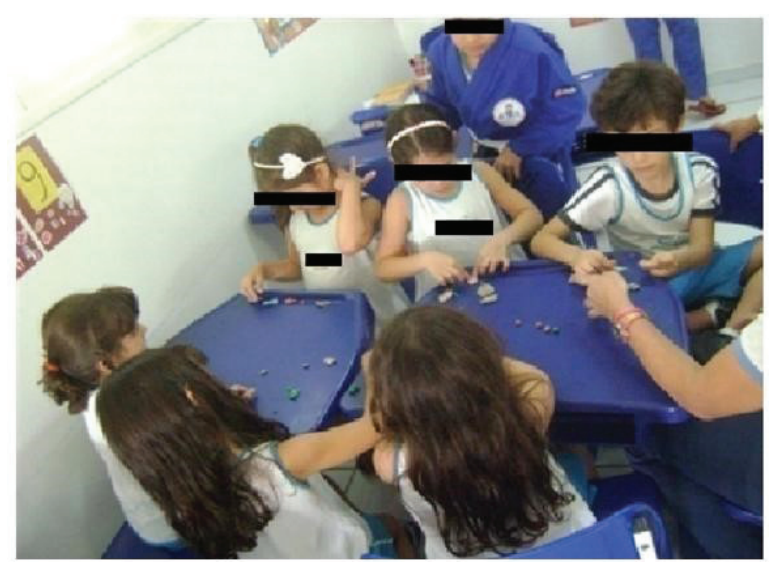

Fonte própria.

Figura 4 - João recebendo apoio da colega na hora da atividade escrita

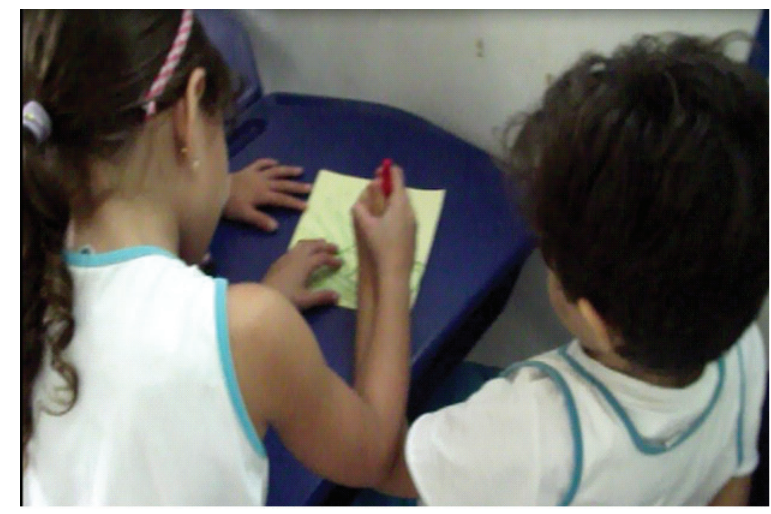

Fonte própria.

Na figura 3, os alunos brincam de massinha após intervenção da professora. $\mathrm{Na}$ figura 4, uma colega de turma auxilia João a fazer um registro escrito durante uma atividade cooperativa proposta pela docente.

As figuras 5 e 6 sugerem que o aluno alcançara os objetivos 1 a 4 da escrita, assinalados no quadro 1 . 
Figura 5 - Escrita do nome

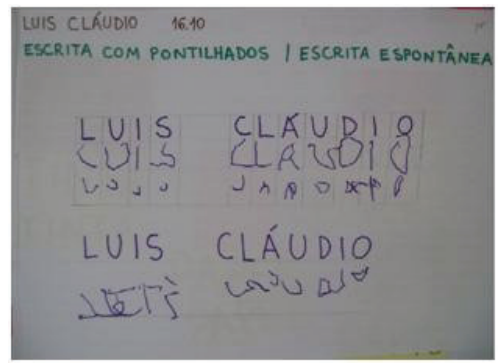

Fonte própria.

Figura 6 - Escrita do nome da escola com técnica de letras vazadas

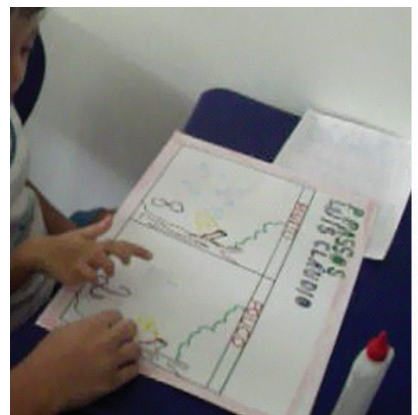

Fonte própria.

Nas atividades acima, João escreve o próprio nome e o nome da escola, utilizando a técnica das letras pontilhadas e vazadas. Vale ressaltar que sua produçấo aproxima-se da escrita convencional das letras.

Os registros escritos observados na figura 7 sugerem que João foi capaz de registrar os acontecimentos sobre seu final de semana, como também de comunicá-los, através de imagens, para a sua turma (objetivo 5 da escrita). 
Figura 7 - Registros sobre o final de semana

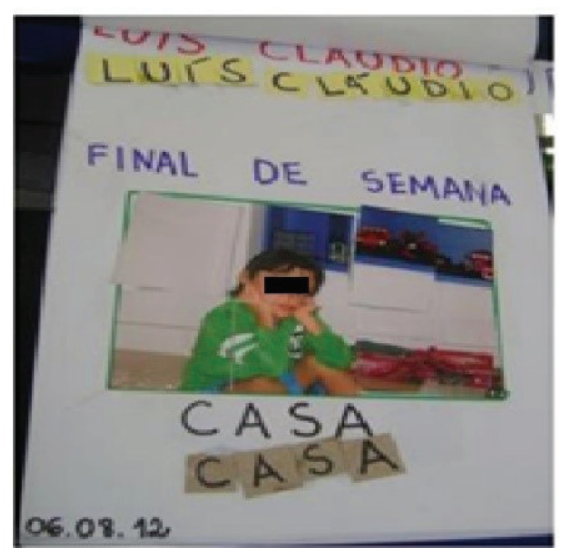

Fonte própria.

Figura 8 - Pareamento de sílabas sobre o projeto de São João

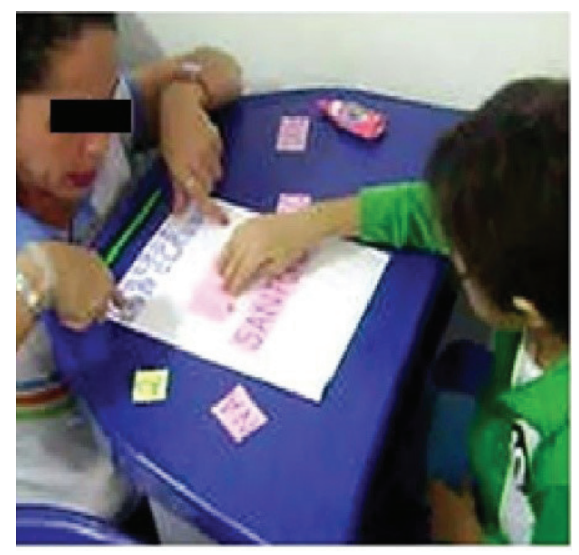

Fonte própria.

As figuras 9 e 10 apontam avanços no desenvolvimento do desenho de João. Especificamente, na atividade da figura 9 ele não só estruturou seu esquema corporal (objetivo 8 da escrita), como também representou o sol e o chão a partir de um modelo desenvolvido pela professora. $\mathrm{Na}$ tarefa da figura 10 , João deu continuidade ao desenho sobre o trânsito, iniciado pela professora (objetivo 9 da escrita). 
Figura 9 - Desenho do esquema corporal

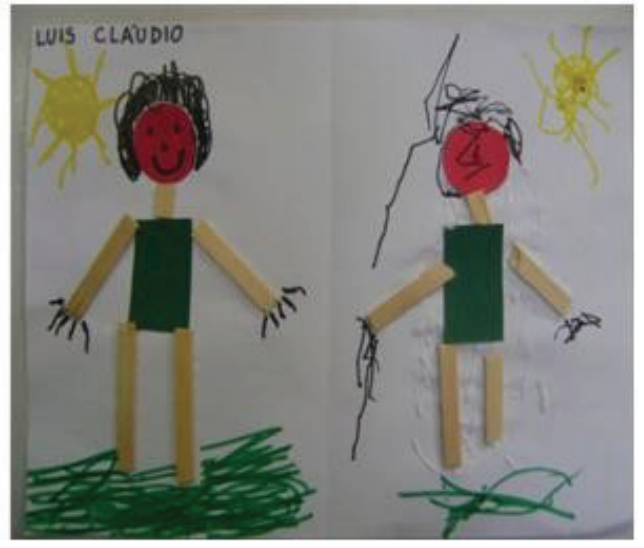

Fonte própria.

Figura 10 - Desenho do trânsito

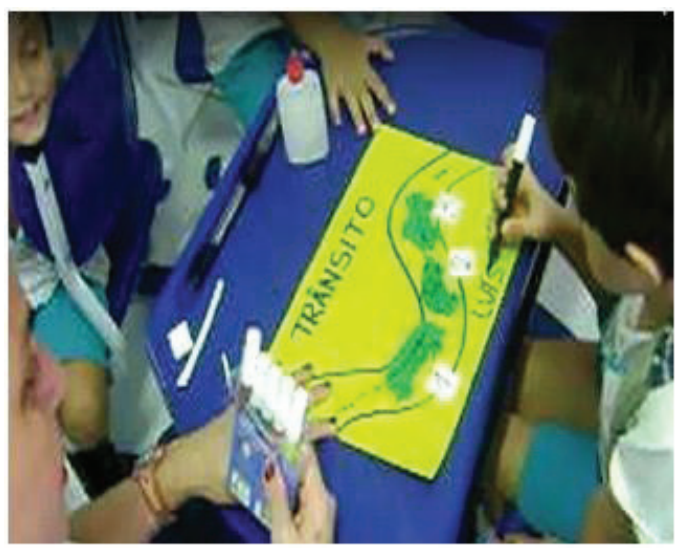

Fonte própria.

Os registros sobre o momento do lanche observado na figura 11 sugerem que a criança atingiu os objetivos 1 e 2 do lanche, ou seja, foi capaz de tomar suco no copo e consumir o lanche oferecido pela escola. 
Figura 11 - João tomando suco no copo e consumindo lanche da escola

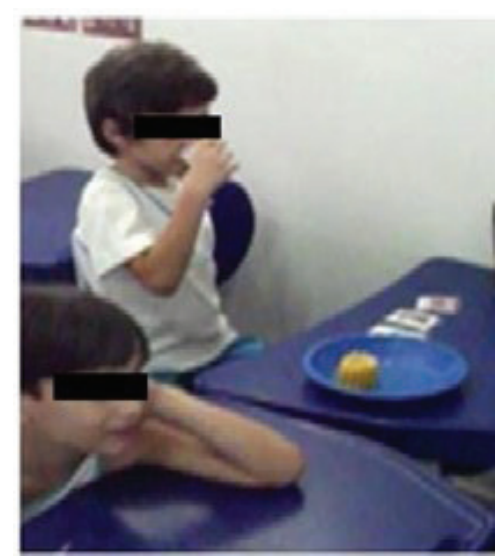

Fonte própria.

Quanto aos registros sobre suas formas de comunicação, a figura 11 indica o uso dos pictogramas para solicitar o lanche à professora (objetivo 3 do lanche).

Figura 12 - João solicitando o lanche à professora auxiliar

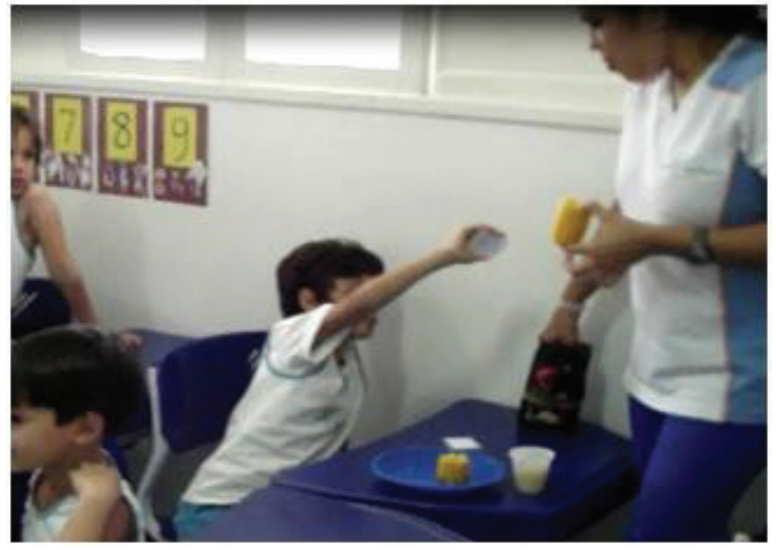

Fonte própria. 
Em termos quantitativos, um delineamento de pesquisa quase-experimental intrassujeito foi utilizado para avaliar os efeitos do PEI no nível de participação do aluno nas rotinas foco da intervenção. Assim, foi contabilizado o tempo que João permaneceu realizando cada tarefa durante a linha de base e, posteriormente, na intervenção, após implementado o PEI. Na tarefa de escrita, os seguintes dados (Figura 13) foram produzidos:

Figura 13 - Tempo de permanência na tarefa escrita

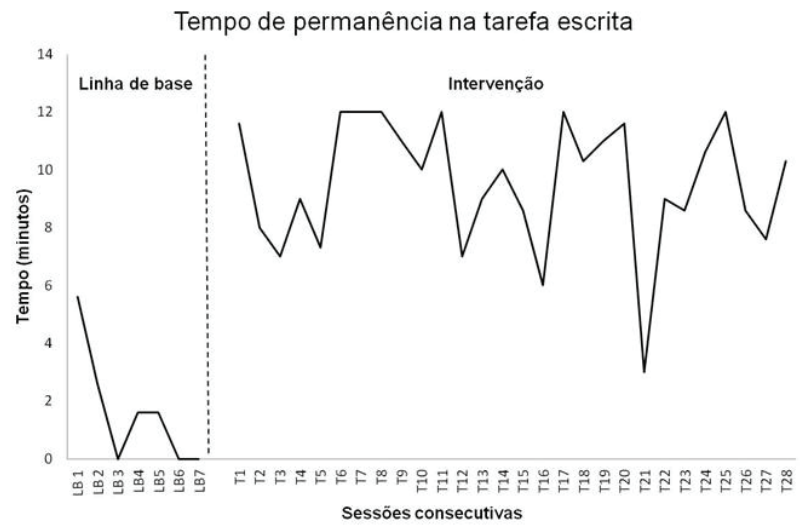

Fonte própria.

Os dados da figura 13 revelam aumento no tempo de permanência na tarefa envolvendo a escrita, após a implementação do programa. Por outro lado, mudanças discretas foram identificadas na rotina do lanche, conforme observado na figura 14. 
Figura 14 - Tempo de permanência no lanche

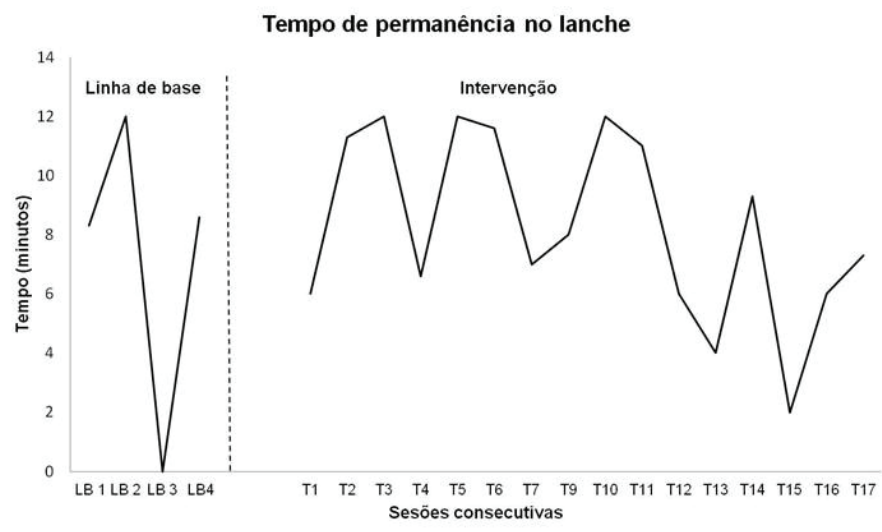

Fonte própria.

Com exceção do segundo registro de linha de base, o aluno não aparentava dificuldades em manter-se engajado durante a tarefa do lanche. Em geral, conseguia permanecer lanchando, junto aos demais, por período entre 5 e 12 minutos. Os ganhos na atividade de alimentação foram mais qualitativos do que quantitativos, uma vez que o João foi capaz de alimentar-se de forma independente, utilizando copo e solicitando os próprios alimentos, conforme assinalado previamente.

Nessas sessôes foi observado o uso dos recursos da CAA durante o lanche, a substituiçáo da mamadeira pelo copo e a ingestáo de alimentos da escola. Embora não previsto nos objetivos do PEI, alguns alunos da turma começaram a utilizar os pictogramas com João. Esse comportamento é ilustrado nas figuras 15 e 16, onde uma colega mostra o cartão ao aluno e o ajuda a lavar as mãos: 
Figura 15 - Colega comunicando a João para lavar as mãos

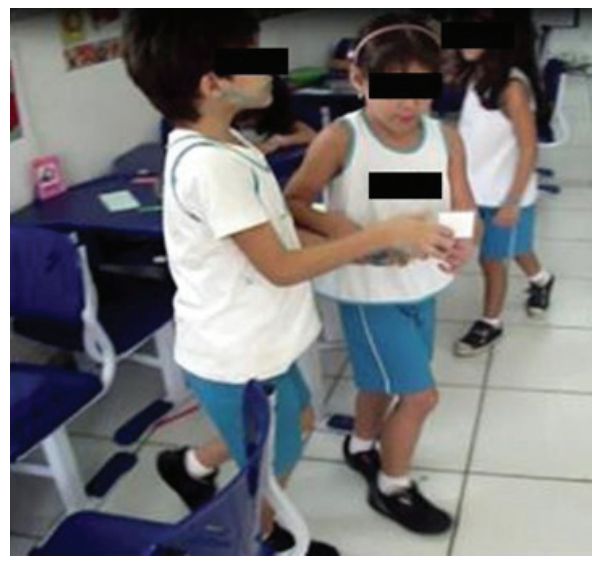

Fonte própria.

Figura 16 - Colega auxiliando João a lavar as mãos sujas de tinta

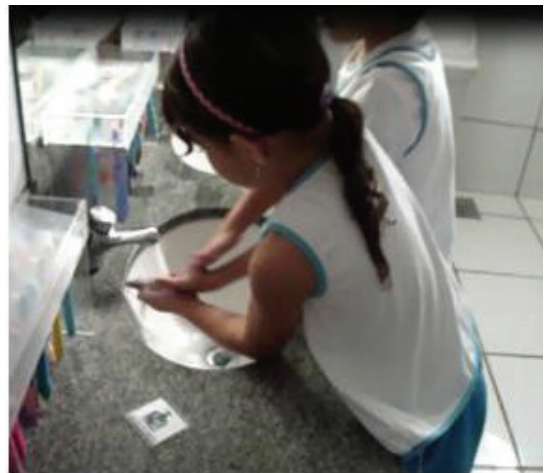

Fonte própria.

Os registros de validação social revelaram que a professora titular concebeu o PEI como um instrumento norteador de seu trabalho pedagógico, que viabiliza a educação do aluno com TEA. Essas ponderaçóes são ilustradas no seguinte segmento, quando a pesquisadora pede que ela fale sobre o PEI: 
Uma coisa fundamental...momento muito importante porque termina fazendo com que o professor pare e comece a perceber o que pode fazer para ele atingir os objetivos... lançar desafios de acordo com as suas capacidades... acho sinceramente um trabalho de uma riqueza tamanha, eu me vi como mãe do meu filho na escola... e era isso que eu gostaria que meu filho tivesse, esse acompanhamento dessa forma ..qual é mãe que não quer ver o seu filho avançando? (Professora titular, 2012).

Essa fala consolida a importância do uso do PEI, numa perspectiva colaborativa, na educação de pessoas com TEA.

\section{Considerações finais}

Os resultados desse estudo revelam a eficácia do programa interventivo proposto, tanto no processo de escolarização do aluno, quanto na prática das docentes. Em termos acadêmicos, foram observadas melhorias na qualidade e tempo de permanência do aluno nas atividades de escrita após a implementação do PEI. Quanto às habilidades funcionais foram registrados avanços nas formas de comunicação da criança, que passou a interagir com os colegas e a utilizar um sistema pictográfico de CAA para solicitar alimentos. Mudanças qualitativas foram, ainda, identificadas, na medida em que o menino desenvolveu um repertório de comportamentos equivalente à de seus pares. Dados observacionais indicaram, por fim, mudanças na prática docente, viabilizadas pelo uso de estratégias colaborativas de intervenção, de cunho teórico-prático, operacionalizadas através de procedimento de autoscopia.

Limitaçóes são identificadas nesta pesquisa. Primeiramente não foram registrados dados de follow-up que pudessem indicar se os efeitos da intervenção foram mantidos ao término do trabalho da pesquisadora. Ademais, por intercorrências previamente discutidas, a participação de agentes interventivos chave, como os pais e a terapeuta ocupacional, foi minimizada, afetando a dinâmica proposta pelo PEI. A despeito das barreiras identificadas, o presente estudo apresenta diretrizes importantes para realizar adaptaçóes curriculares, de cunho colaborativo, por meio do PEI.

\section{Referências}

BENTES, Clênya; COLARES, Maria; Adailson, SOARES. Família e escola: uma proposta para a gestẫo compartilhada. VII Seminário Regional de Política e Administração da Educação do Nordeste. Universidade Federal de Pernambuco. Anais Políticas, práticas e gestão da educaçāo. Anais, ISSN: 1677-3802. Biblioteca ANPAEsérie cadernos, 2012.

BRASIL. Ministério da Educação. Referencial Curricular Nacional para a Educação Infantil. Brasília, DF, 1998, 85 p.

BRASIL. Ministério da Educação. Instituto Nacional de Estudos e Pesquisas Anísio Teixeira (INEP). Censo Escolar 2017: notas estatísticas. Brasília, 2018.

FAGUNDES, Antônio. Descriçáo, definiçáo e registro de comportamentos. $14^{a}$ Ed. São Paulo: Edicon, 2006.

FARIAS, Iara Maria; MARANHÃO, Renata Veloso; CUNHA, Ana Cristina Barros da. Interação professor-aluno com autismo no contexto da educaçáo inclusiva: análise do padrão de mediaçáo do professor com base na Teoria da Experiência de Aprendizagem Mediada (Mediated Learning Experience Theory). Rev. Bras. Ed. Esp, Marília, v.14, n. 3, p.365-384, 2008. 
FEUERSTEIN, Reuven; RAND, Yaacov; JENSEN, Mogens; KANIEL, Shlomo; TZURIEL, David. Prerequisites for assessment of learning potential: The LPAD model. In: LIDZ, Carol (Org.). Dynamic assessment: an interactional approach to evaluating learning potential. New York/London: Guilford Press, 1987. p.35-51.

FERREIRO, Emília. TEBEROSKY, Ana. Psicogênese da Língua Escrita. Trad. Diana Myrian Lichtenstein et all. Ed. Artmed, Porto Alegre, 1999.

GANZ, Jennifer. AAC interventions for individuals with autism spectrum disorders: State of the science and future research directions. Augmentative and Alternative Communication, Vancouver, v.3, n.3, p. 203-214, 2015.

GLAT, Rosana; PLETSCH, Márcia Denise. Inclusáo escolar de alunos com necessidades educacionais especiais. Editora Eduerj, Rio de Janeiro, 2011. (Série Pesquisa em Educação)

KISHIMOTO, Tizuko Morchida (org.). Jogo, brinquedo, brincadeira e a educaçăo. 5. ed. São Paulo: Cortez, 2001.

LOPES, José; SILVA, Helena Santos. Aprendizagem Cooperativa na sala de aula: um guia prático para o professor. 1. ed. Lisboa: Lidel, 2009.

MACÊDO, Cláudia Roberto; NUNES, Débora Regina de Paula. Aprendizagem mediada na escolarização de educandos com autismo. Revista Educaçáo em Questáo, Natal, v.54, n. 42, p.135-160, 2016.

MOREIRA, Ana Angélica Albano. O espaço do desenho: A educação do educador. São Paulo: Ediçōes Loyola, 1984 .

NOZI, Gislaine Semcovici; VITALIANO, Célia Regina. O professor e o processo de inclusão de alunos com necessidades educacionais especiais: análise de pesquisas publicadas no site da Anped. V Congresso Brasileiro de Educação Especial, VII Encontro Nacional de Pesquisadores da Educação Especial. Universidade Federal de São Carlos, 2012.

NEVES, Anderson; ANTONELLI, Carolina, SILVA, Mariana; CAPELLINI, Vera. Escolarização formal e dimensôes curriculares para alunos com autismo: o estado da arte da produçấo acadêmica brasileira. Educaçáo em Revista, Belo Horizonte, v. 30, n.2, p.43-70.

NUNES, Débora Regina de Paula; SCHMIDT, Carlo; AZEVEDO, Mariana Queiroz Orrico. Inclusão educacional de pessoas com Autismo no Brasil: uma revisão da literatura. Revista Educaçáo Especial, Santa Maria, v. 26, n. 47, p. 557-572, 2013.

OLIVEIRA, Juliana; PAULA, Cristiane. Estado da arte sobre inclusāo escolar de alunos com transtornos do espectro do autismo no Brasil. Cadernos De Pós-Graduaçáo em Distúrbios do Desenvolvimento, São Paulo, v.12, n.1, p. 53-65.

PEREIRA, Alessandra; RIESGO, Rudimar; WAGNER, Mario. Autismo infantil: tradução e validação da Childhood Autism Rating Scale para uso no Brasil. J. Pediatr, Rio de Janeiro, v.84, n.6, p.487- 494, 2008.

POLONIA, Ana da Costa; DESSEN, Maria Auxiliadora. Em busca de uma compreensão das relaçốes entre família escola. Psicol. Esc. Educ., Campinas, v. 9, n. 2, p. 303-312.

SADALLA, Ana Maria; LAROCCA, Priscila. Autoscopia: um procedimento de pesquisa e de formação. Educaçáo e Pesquisa, São Paulo, v.30, n.3, p. 419-433, set./dez. 2004. Disponível em http://www.scielo.br/pdf/ep/ v30n3/a03v30n3.pdf. Acesso em 18 Dez 2013.

SCHMIDT, Carlo; NUNES, Débora Regina de Paula; PEREIRA, Débora Mara; OLIVEIRA, Vivian; NUERNBERG, Adriano; KUBASKI, Cristiane. Inclusáo escolar e autismo: uma análise da percepçấo docente e práticas pedagógicas. Revista Psicologia: teoria e prática, Universidade Presbiteriana Mackenzie, São Paulo, 2016. Disponível em: http://editorarevistas.mackenzie.br/index.php/ptp/article/viewFile/9357/5721. Acesso em 5 Junho 2018.

SMITH, Deborah Deutsch. Introdução à Educação Especial: Ensinar em tempos de inclusão. Tradução M.A. Almeida. São Paulo: Artmed, 2008.

\section{Notas}

${ }^{1}$ Autoscopia compreende um procedimento investigativo que visa a autoavaliaçáo do sujeito participante por meio da videogravação de sua atuação, servindo também como instrumento de formaçâa. A videogravação é o instrumento mais apropriado para serem revividos situaçóes, interaçôes e objetos por um sujeito, em determinada realidade (SADALLA E LAROCCA, 2004). 
${ }^{2}$ Feurstein e colaboradores (1987) desenvolveram um modelo interventivo denominado de Experiência de Aprendizagem Mediada (EAM), que contempla um conjunto de açóes propositivas de um mediador, com maior nível de desenvolvimento, que seleciona, modifica, amplia e/ou interpreta os estímulos ambientais para um aprendiz, tornando-o mais autônomo e independente.

\section{Correspondência}

Débora Mara Pireira - Universidade Federal do Rio Grande do Norte (UFRN), Av. Sen. Salgado Filho, 3000, Lagoa Nova, CEP: 59078-970. Natal, Rio Grande do Norte, Brasil.

E-mail: deborareginanunes@yahoo.com - deboramaraa@hotmail.com

Recebido em 25 de julho de 2018

Aprovado em 8 de agosto de 2018

\section{(c) (i) (8)}

This work is licensed under a Creative Commons Attribution-NonCommercial 4.0 International (CC BY-NC 4.0) 